\title{
Differentiation Research of Daily Ceramic Products
}

\author{
Tao Tao \\ Jingdezhen Ceramic University \\ Jingdezhen, China 333001 \\ Huaiyin Institute of Technology \\ Huai'an, China 223001
}

\author{
Xiaosong Zou \\ Jingdezhen Ceramic University \\ Jingdezhen, China 333001
}

\begin{abstract}
The phenomenon of homogenization of daily-use ceramics in China is relatively serious. It is difficult to meet the diversified consumer demand for daily-use ceramic products, and it also makes the enterprises less competitive. This article starts with the transformation of contemporary social consumer ideas, and then puts forward that daily ceramic products should focus on the differentiation of design, production and sales, in order to solve the conflicts between product homogeneity and the diversified consumer demands, and to promote the development of China's ceramic products for daily use.
\end{abstract}

Keywords-daily-use ceramics; demand; differentiation; marketing

\section{INTRODUCTION}

China, as a major producer of ceramics, exported 23.43 million tons of ceramics in 2017, with an output value of $19,249,212$ thousand US dollars (according to the data from the China National Industrial Research Institute). China has a number of important ceramic production areas with production companies large and small, ranking first in production capacity worldwide. According to statistics, the world's $60-70 \%$ of daily-use ceramic products is made in China. Although the amount of daily-use ceramics products produced in China on the market is huge, homogeneity is serious, and product modeling and decoration are similar, which is largely due to the lack of design, plagiarism, lack of innovation and other factors. It also cut down the added value of China's ceramic products for daily use, thus making the products less competitive internationally, and unable to meet the extensive needs of the market and consumers.

\section{THE CHANGE OF MODERN CONSUMPTION CONCEPT AND THE DIVERSIFICATION OF THE DEMAND FOR DAILY-USE \\ CERAMIC PRODUCTS}

Since the Reform and Opening-up, China's economy has achieved tremendous development. People's living standards and purchasing power have also been greatly improved. With the transformation of China into a consumer society, people's consumption ideas and the degree of pursuit of goods have also changed. In the past, people paid more attention to the use of items, and now they are more in pursuit of the aesthetic function of objects. The idea of materialistic frugality in the past was replaced by the concept of replacement of the consumer society. People want to obtain better and more beautiful objects, and even begin to pursue the symbolic functions of objects, that is, new human relationships and social identification systems embodied by objects. Therefore, people focus more on pursuing the differentiation and personalization of objects to embody their identities and values through consumption. Daily-use ceramic products are the most common daily necessities, covering all aspects of daily life, such as tableware, tea sets, and flower arrangements. People demand for ceramic products also changes along with changes in consumer attitudes, and they tend to be diversified in general. People buy various ceramic products according to their own economic conditions, aesthetic tendencies, and environmental identities to meet their own special needs Therefore, the design and production of ceramic products should have a differentiated response. Marketing strategies should also be rich, varied, and focus on the modern media platform.

\section{DIFFERENT STRATEGIES FOR DAILY CERAMIC PRODUCTS}

The strategy of differentiation of daily-use ceramic products should be reversed from sales to production and marketing. The design process should come first before the production of products. Through differentiated design, production, and marketing, it will meet the diversified needs of ceramic products.

\section{A. The Difference in the Design and Production of Daily- use Ceramic Products Mainly Includes Horizontal and Vertical Differentiation of Products}

Horizontal differentiation points to the appearance of the product, while vertical differentiation points to the product intrinsic. These two types of differentiated re-product design and production are mutually reinforcing and mutually satisfying.

1) Horizontal differentiation of daily ceramic products: Horizontal differentiation refers to a product in which some consumers prefer a certain feature while others another feature. The main cause of this difference in the consumption of ceramic products is the consumer's different preference for product modeling and decoration. The socalled "radish greens and vegetables have their own love." Everyone has their own favorite styles and ornamentation. 
People of all ages have different preferences, different cultural levels, and spending power. The outstanding performance of homogenization of daily-use ceramic products is precisely the similarity of product modeling and decoration (glaze color, ornamentation). Some products are too dependent on traditional classics and exotic types and ornamentation in modeling and decoration, lacking autonomous creativity; some will transform traditional classics and exotic devices, but the alteration is simple and the products are similar, lacking original design. The combination of patterns and textures is blunt and lacks a harmonious aesthetic sense; some artifacts lack the consideration of human-machine combination factors, thus inconvenient for the actual use of consumers.

In order to overcome the above deficiencies, first of all, we should strengthen the original design of daily-use ceramic products, and create more models and textures with a sense of the times and modern aesthetics. Modeling and ornamentation are the most intuitive product impressions. Consumers often make quick judgments when they first see it. This kind of judgment will have a significant impact on the purchasing behavior. Designers and companies should therefore produce more product choices rather than relatively single choices, because in the case of multiple choices, there is always a greater chance that "there will be one that you like". A Western ceramic company often has more than 1,000 kinds of design of patterns at the same time, to provide consumers with choices, while China's ceramic companies have relatively few patterns. Although the reasons for this situation are manifold, e.g. the issue of development cost is also related to production efficiency, but the main reason is still the design problem. The lack of innovation and the monolithic product categories have apparently failed to meet market and consumer demands.

Secondly, companies and product designers should pay attention to market research---the collection and research of product feedback, so as to produce more and more targeted appearance and personalized products according to market demand. Since consumers' personal preferences vary widely, but the types of ceramic products are always limited, private customization can be carried out and precise production can be made to meet the individual needs of consumers with more spending power. Enterprises should have the ability to respond quickly to customer needs and to produce quickly. As the world's largest production and export base for dailyuse ceramics, Fengxi Guangdong responds quickly to customer requirements, shortening the time from design to production of samples to three days. This design and production capability is undoubtedly the very important competitiveness of the company.

Finally, the production of daily-use ceramic products should be carried out in parallel with the manual production and machine production methods. It is not possible to abandon hand-made porcelain because of the high productivity of machine production. (Facts have proved that the use of machines to completely replace manual production is catastrophic for the development of ceramics in China. There is already a lesson from the past). Hand-made is
China's tradition of making porcelain. This is the way that cannot be imagined and compared by the western porcelainbased porcelain making. This is also the practical strengths and advantages of China's ceramic industry. Compared to the uniform and intellectual indifference of machine products, hand-crafted objects have emotional significance due to the joining of people's postures (Jean Baudrillard), reflecting the needs of human nature and emotion in contemporary society. The use of hand-manufactured ceramics also has a special aesthetic experience and higher economic added value, which is an important aspect of differential production of daily-use ceramics.

2) Longitudinal differentiation of daily-use ceramic products: Most consumers prefer products with certain characteristics. The differentiation of such products is called "differentiation in the vertical." The study of vertical differentiation mainly revolves around product quality and performance. The production of ceramic products for daily use not only requires more efforts in modeling and decoration, but also differentiates and enhances materials and technology. High-end products must be differentiated from ordinary products in terms of technology, quality, strict specifications, and high standards. The low-end and middle-end products pay attention to cost control and industry standards, and are distinguished from inferior products.

Usability is the primary goal of daily-use ceramic products. Daily-use ceramic products were originally manufactured for people's daily use. "Easy use" is an important criterion for judging the quality of daily ceramic products as well as an important factor in product differentiation. Materials have a very important influence on the reliability and usability of ceramics. The price difference between good ceramic materials and general ceramic materials is nearly 10 times (Jingdezhen's finest china clay is a few thousand yuan per ton, and ordinary china clay is only a few hundred yuan per ton.). Good ceramic materials must be used to make high-grade ceramics, which determines the differentiation of product quality and appearance design. In addition, companies should associate surface-oriented design and decoration with the internal structure of ceramic products to produce products with both aesthetic appeal and functionality. The teapot designed by the first president of the Bauhaus school, Gropius, for Rosenthal in the 1960s, whose center of deflection and its position near the handle is not just for formalism, but rather the convenience of usage. The purpose of functionalism, combined with the ingenious design of a person's single-handed use of the pot, is such that the thumb can easily hold down the lid to make it easy to use (the traditional teapot lid is located in the center line of the kettle body, so the kettle lid is far from the thumb and can be easily damaged if the pot is held with one hand.) The material selection, structural design, and quality standards of the products are important reasons for vertical differentiation of the products. Attention should be paid to the design and production of daily-use ceramic products. 


\section{B. Differentiation of Marketing Ceramics for Daily Use Ceramics}

In addition to implementing differentiated strategies in production and design, it is also necessary to implement differentiated sales strategies based on target groups in the marketing segment. A good marketing strategy plays an important role in the consumption of products, and it also emphasizes and highlights the differentiation of product design and production. The most important thing in marketing is the promotion of products, especially through modern media. For daily-use ceramic products, the low-end market should place importance on practicality and propaganda, the mid-market should pay attention to aesthetic propaganda, and the senior market should pay more attention to cultural propaganda. People's consumer psychology has both the trend of conformity and the performance of seeking differences. Therefore, it can be promoted by means of modern media. Consumers with more spending power tend to be more congenial. For example, advertisements say "This is what everyone likes to use." Consumers with higher levels of consumerism are more concerned with differentiation, and are more likely to accept such slogans: "This item is unique", "This item is tailor-made for you" and "This is a well-known brand." Sales of ordinary ceramic products should highlight practicability, while high-end porcelain should be more emphasized on aesthetics and brand. In addition, sales should consider the convincing power of ceramic culture, promote ceramic culture, pay attention to environmental protection, health and ecology and so on.

\section{CONCLUSION}

At present, the current situation of the homogeneity of daily-use ceramic products in China can neither meet the needs of the market, nor the needs of individual diversification, nor the needs of the rejuvenation of Chinese ceramics in the era of globalization. Therefore, the daily ceramic products should adopt a diversified and differentiated strategy in the design, production and sales. In this way, the development of China's daily-use ceramics industry will usher in a truly brilliant future.

\section{REFERENCES}

[1] Li Zhengan, Ceramic Design, Hagzhou:China Academy of Art Press, 2003.

[2] Jean Baudrillard, System of Objects, translated by Lin Zhiming, Shanghai: Shanghai People's Publishing House, 2001.

[3] Pierre Bourdieu, distinction, translated by Liu Hui, Beijing: Commercial Press, 2015. 